\title{
FORMULASI STRATEGI BISNIS PERUSAHAAN ORIGINAL EQUIPMENT MANUFACTURER (OEM) STUDI KASUS DI PT XYZ
}

\author{
FORMULATION STRATEGY BUSINESS OF THE ORIGINAL EQUIPMENT MANUFACTURER(OEM) \\ COMPANY CASE STUDY AT PT XYZ
}

\author{
Puryani $^{*}{ }^{1}$, Lukman Muhammad Baga ${ }^{* *}$, dan Imam Teguh Saptono ${ }^{*}$ \\ ${ }^{*}$ Sekolah Bisnis, Institut Pertanian Bogor \\ Jl. Raya Pajajaran, Bogor 16151 \\ ${ }^{* *}$ Departemen Agribisnis, Fakultas Ekonomi dan Manajemen, Institut Pertanian Bogor \\ Jl. Kamper, Wing 4 Level 5, Kampus IPB Darmaga, Bogor 16680
}

\begin{abstract}
The objectives of this study are to describe the vision and mission, to analyze internal and external conditions, and to formulate strategy of PT XYZ. The research was carried out by descriptive analysis method. The tools used at this study included IFE (Internal Factor Evaluation), EFE (External Factor Evaluation), IE (Internal-External) and QSPM (Quantitative Strategic Planning Matrix). The study showed that the vision of the company is in accordance with the goals of the company, whereas the mission analysis identified that not all members of the company know the company mission. Internal analysis shows 8 factors becoming the strengths and 8 factors becoming the weaknesses for the company, while the external analysis shows 7 factors becoming the opportunities and 7 factors becoming the threats for the company. The IFE and EFE matrix analysis showed scores of 3,064 and 2,595. This score showed that the company position is on the IE matrix, quadrant I (cell IV). In this quadrant, the right strategy is to grow and build. Alternative strategies formulated for the company include market penetration, product development, people development, market development, company relocation and competitive pricing. Based on the QSPM matrix, the priority strategy formulated for PT XYZ is people development.
\end{abstract}

Keywords: alternative strategies, IFE, EFE, IE, QSPM

\begin{abstract}
Abstrak: Penelitian ini bertujuan mendeskripsikan visi dan misi, menganalisis kondisi internal dan eksternal serta merumuskan strategi PT XYZ. Penelitian dilakukan melalui metode pendekatan analisis deskriptif. Alat analisis yang digunakan, yaitu matrix IFE (Internal Factor Evaluation), EFE (External Factor Evaluation), IE (Internal-External) dan QSPM (Quantitative Strategic Planning Matrix). Hasil penelitian dapat diidentifikasi bahwa visi perusahaan saat ini sudah sesuai dengan tujuan dan cita-cita perusahaan, sedangkan pada analisis misi dapat diidentifikasi bahwa belum semua anggota perusahaan mengetahui misi perusahaan. Hasil analisis lingkungan internal menghasilkan 8 faktor yang menjadi kekuatan dan 8 faktor yang menjadi kelemahan perusahaan, sedangkan hasil analisis lingkungan eksternal menghasilkan 7 faktor yang menjadi peluang dan 7 faktor yang menjadi ancaman perusahaan. Analisis matrik IFE dan EFE menghasilkan skor 3,064 dan 2,595. Skor ini memposisikan perusahaan pada pada matrik IE, yaitu kuadran I (sel IV). Pada kuadran ini strategi yang tepat adalah grow and build. Alternatif strategi yang berhasil dirumuskan adalah penetrasi pasar, pengembangan produk, pengembangan SDM, pengembangan pasar, relokasi perusahaan dan menetapkan harga bersaing. Berdasarkan matrik QSPM, strategi prioritas yang berhasil dirumuskan adalah pengembangan SDM.
\end{abstract}

Kata kunci: alternatif strategi, IFE, EFE, IE, QSPM

\footnotetext{
${ }^{1}$ Corresponding author:

Email: pury.mgt2@gmail.com
} 


\section{PENDAHULUAN}

PT XYZ merupakan salah satu perusahaan Original Equipment Manufaturer (OEM) yang bergerak dalam bidang produksi footwear. Produk yang dihasilkan adalah sepatu. OEM adalah perusahaan yang memproduksi produk atau komponen yang dibeli oleh perusahaan lain dan dijual dengan merek perusahaan pembeli (Chen, 2010). Sebagai perusahaan OEM, PT $\mathrm{XYZ}$ hanya memproduksi produk berdasarkan pesanan dari pelanggan. Perusahaan yang menjadi pelanggan PT XYZ adalah brand internasional sehingga sebagian besar produk yang dihasilkan adalah untuk ekspor. PT $\mathrm{XYZ}$ juga menghasilkan produk dengan brand sendiri (own brand) tetapi persentase penjualannya masih sangat kecil yaitu hanya sekitar $1-3 \%$ dari total produk yang dihasilkan dan pemasarannya masih di dalam negeri. Masih kecilnya persentase produk own brand menjadikan PT XYZ saat ini masih bergantung dengan pesanan produk dari OEM.

Sebagai perusahaanjasa, kepuasan pelanggan merupakan faktor yang sangat penting. Hal ini disebabkan karena kepuasan pelanggan merupakan salah satu faktor yang menjamin kontinyuitas pesanan. Piri (2013) menyatakan bahwa kepuasan pelanggan dapat memengaruhi perilaku pelanggan khususnya loyalitas pelanggan, selain itu hasil karya dan kualitas produk, kualitas pelayanan dan kinerja yang baik juga sangat menunjang kepuasan pelanggan. Bask et al. (2010) menyatakan bahwa kesesuaian strategi palayanan, model bisnis dan bisnis proses merupakan faktor penting dalam mendukung efektifitas pelayanan terhadap pelanggan. Normasari et al. (2013) menyebutkan bahwa kualitas pelayanan secara langsung memiliki pengaruh yang signifikan terhadap kepuasan pelanggan dan kualitas pelayanan secara langsung memiliki pengaruh yang signifikan terhadap citra perusahaan. Bae (2012) menyebutkan bahwa kemampuan perusahaan dalam membuat differensiasi produk akan memengaruhi kepuasan pelanggan dan secara alami akan berpengaruh terhadap loyalitas pelanggan.

PT XYZ sangat mengutamakan kepuasan pelanggan sehingga sangat memperhatikan tiga hal yang selalu dituntut pelanggan yaitu pengiriman tepat waktu, kualitas yang sesuai standar dan harga yang kompetitif. Untuk mewujudkan tiga hal tersebut PT XYZ harus mempunyai strategi yang tepat agar perusahan dapat bertahan dan bersaing dengan kompetitor. Wicaksono (2017) menyebutkan bahwa dalam persaingan dunia bisnis yang semakin ketat serta perkembangan teknologi yang semakin canggih dan modern, membuat perusahaan berusaha mencari strategi yang cepat dan tepat dalam memasarkan produk untuk memenuhi kebutuhan industri. Ribek (2016) menyebutkan bahwa persaingan yang ketat akan memotivasi manajemen perusahaan untuk memberikan pelayanan terbaik kepada pelanggannya. Rivai dan Prawironegoro (2015) menyebutkan bahwa keberhasilan adalah perpaduan yang baik antara strategi dan pelaksanaannya. Strategi yang efektif akan membuat perusahaan lebih kompetitif (Ehie dan Muogboh, 2016).

Pada perumusan strategi, perusahaan harus mengetahui kekuatan, kelemahan, peluang dan ancaman. Perusahaan yang tidak melakukan analisis terhadap kekuatan, kelemahan, peluang dan ancaman maka perusahaan tersebut tidak akan produktif. Osita et al. (2014) menyatakan bahwa agar sebuah organisasi benar-benar tetap stabil dan usahanya produktif harus melakukan identifikasi apa yang membentuk kekuatan, kelemahan, peluang dan ancaman, jika sebuah organisasi tidak mengidentifikasi kekuatan, kelemahan, peluang dan ancamannya maka organisasi tersebut pasti akan gagal dalam bidang produktivitas karena organisasi tersebut tidak akan stabil. Nurseto (2012) menyatakan bahwa semua variabel lingkungan industri berpengaruh terhadap perusahaan karena lingkungan industri bersifat dinamik dan sangat memengaruhi perusahaan dalam menetapkan strategi agar dapat bersaing dan menjaga keberlangsungan usaha. Biodi dan Sanawiri (2017) menyebutkan bahwa agar perusahaan mampu mempertahankan eksistensinya maka setiap pelaku bisnis perlu membuat perencanaan jangka panjang dan menentukan strategi bersaing yang perlu diambil perusahaan. Hashim (2016) yang menyatakan bahwa strategi bisnis di berbagai organisasi dikembangkan melalui pendekatan strategis yang berbeda. Perbedaan pendekatan dari satu dengan yang lain terjadi karena perbedaan dalam hal kompleksitas, fokus strategis dan cakupannya. Prasad (2010) menyatakan bahwa memahami perbedaan antara strategi dan efektivitas operasional sangat penting. Hutahaean et al. (2017) menyebutkan bahwa melalui strategi membangun mekanisme kerja yang tepat dan baik sesuai dengan struktur organisasi perusahaan dapat meningkatkan efesiensi kerja karyawan. Singh (2016) menyebutkan bahwa pada industri alas kaki strategi penetapan harga yang tepat dan kepuasan pelanggan merupakan faktor yang paling dominan dalam memengaruhi kesetiaaan pelanggan. 
Target penjualan PT XYZ adalah brand-brand besar yang sudah mempunyai brand image yang kuat dan volume penjualan yang besar. Brand image berpengaruh signifikan terhadap brand loyalty dan brand trust dan brand trust berpengaruh juga terhadap brand loyalty (Bastian, 2014). Li (2013) menyatakan bahwa ada hubungan positif antara image, harga, persepsi kualitas dan nilai yang dirasakan oleh pelanggan (kepuasan pelanggan) yang pada gilirannya akan memengaruhi kesetiaan pelanggan. Sebagai brand besar banyak perusahaan lain atau kompetitor yang ingin menjadi pemasok dan ini menjadikan PT XYZ mempunyai banyak pesaing. Hubungan kerjasama yang dijalankan PT XYZ dengan pelanggan saat ini adalah kerja sama yang dilandasi saling percaya dan tidak ada kontrak kerja. Kontrak kerja hanya sebatas pesanan yang sudah diterima. Hal ini disebabkan karena pelanggan tidak ingin ada keterikatan dengan pemasok-pemasoknya, sehingga pemasok yang bisa memberikan pelayanan terbaik yang akan dipertahankan. Tuntutan pelanggan saat ini adalah produk yang berkualitas, pengiriman tepat waktu dan harga yang kompetitif. PT XYZ saat ini masih belum bisa mewujudkan tuntutan tersebut terutama untuk produk baru karena untuk produksi produk baru sering ada masalah kualitas sehingga pengiriman sering terlambat dan harga lebih mahal jika dibandingkan kompetitor. Hal ini menyebabkan pesanan dari pelanggan mengalami fluktuasi dan belum bisa memenuhi kapasitas terpasang perusahaan yaitu 2 juta pasang per tahun. Fluktuasi kuantiti ekspor selama lima tahun terakhir dapat dilihat pada Gambar 1.

Penelitian pendahuluan yang terkait dengan strategi perusahaan sepatu pernah dilakukan oleh Nurzamzami (2016) yang berjudul peningkatan daya saing UMKM alas kaki di Kecamatan Ciomas, Kabupaten Bogor dan implikasinya terhadap strategi pemasaran dan Chen et al. (2015) yang berjudul survival strategy of OEM companies: a case study of the Chinese toy industry. Persamaan dari kedua penelitian tersebut adalah samasama meneliti bisnis yang bergerak dalam bidang jasa pembuatan produk dan mengidentifikasi kekuatan utama yang berpengaruh pada bisinis perusahaan untuk menentukan strategi yang tepat agar perusahaan mampu menghasilkan keuntungan dan bertahan dalam jangka panjang. Perbedaan dari kedua penelitian tersebut adalah pada UMKM karena sekala bisnisnya lebih kecil maka pada penentuan strategi difokuskan pada identifikasi kekuatan, kelemahan, peluang dan ancaman perusahaan untuk mementukan strategi perusahaan agar perusahaan mampu bertahan dalm jangka panjang. Hasil hasil penelitiannya adalah strategi pengembangan dan perluasan pasar dengan meningkatkan kualitas dan inovasi produk. Pada penelitian tentang strategi perusahaan OEM karena skala bisnisnya lebih besar sudah tidak ada kendala dengan pemasok maupun pelanggan sehingga penelitian difokuskan pada strategi untuk peningkatan profitabilitas perusahaan dan dan berhasil diidentifikasi bahwa faktor utama yang berpengaruh pada margin perusahaan OEM adalah biaya tenaga kerja. Pada penelitian Chen et al. (2015) strategi yang direkomendasikan untuk perusahaan OEM adalah selain menjalankan bisnis OEM perusahaan dapat menjalankan bisnis ODM (Original Design Manufacturer) dan OBM (Original Brand Manufacturer) sebagai bisnis tambahan. Perusahaan OEM yang tidak dapat memperbaruhi bisnisnya maka akan mengalami kecenderungan peningkatan biaya produksi. Salah satu solusi untuk mempertahankan biaya adalah memindahkan perusahaan ke daerah yang biaya tenaga kerjanya lebih rendah. Jika perusahaan OEM tidak ingin memindahkan operasi perusahaannya ke daerah yang berbiaya rendah, salah satu solusi untuk mempertahankan perusahaan adalah meningkatkan investasi pengembangan produk dan meningkatkan kemampuan design produk secara bertahap agar mampu berkembang menjadi ODM. Selanjutnya, perusahaan harus mengembangkan pemasaran dan mengembangkan strategi differensiasi agar mampu berkembang menjadi perusahaan OBM. Penelitian tentang perusahaan OEM ini juga didukung oleh penelitian Yan et al. (2011) yang berhasil mengidentifikasi bahwa pengusaha yang mempunyai kepemimpinan strategis yang mampu mengelola keseimbangan yang halus antara stabilitas dan perubahan dalam perusahaan sehingga mampu memfasilitasi transformasi perusahaan dari OEM ke perusahaan global yang mempraktekkan OBM.

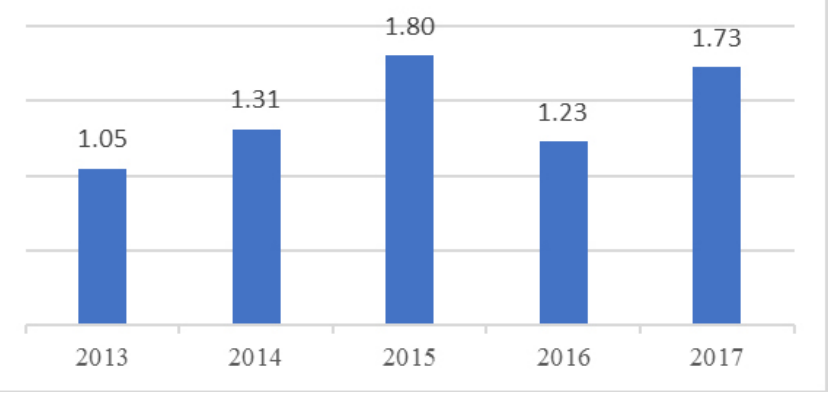

Gambar 1. Fluktuasi jumlah ekspor tahun 2013-2017 (juta pasang) 
Penelitian ini bertujuan mendeskripsikan visi dan misi PT XYZ apakah masih relevan dengan kondisi saat ini, menganalisis kondisi internal dan eksternal PT XYZ dalam merespon peluang dan ancaman bisnis dan merumuskan strategi PT XYZ agar mampu bersaing. Penelitian ini adalah dalam batas ruang lingkup manajemen strategik, khususnya mengenai analisis formulasi strategi yaitu pada PT XYZ. Penelitian ini bersifat melengkapi penelitian yang sudah ada mengenai perusahaan sepatu khususnya OEM. Pendekatan penyelesaian masalah dilakukan dengan cara pengamatan langsung diperusahaan dan menggunakan data internal perusahaan sebagai pendukung, kemudian melakukan wawancara dengan pihak manajemen perusahaan untuk mendapatkan informasi mengenai permasalahan yang dihadapi.

\section{METODE PENELITIAN}

Penelitian ini dilaksanakan dari bulan Februari - April 2018, bertempat di PT XYZ yang terletak di Bogor, Jawa Barat. Penelitian ini menggunakan metode deskriptif analisis dalam bentuk studi kasus. Jenis data yang digunakan adalah primer dan sekunder. Data primer diperoleh melalui observasi, wawancara dan kuesioner. Data sekunder diperoleh dari data internal perusahaan, data dari internet dan studi pustaka. Hipotesis penelitian pada penelitian ini bahwa identifikasi faktor internal dan eksternal dari industri sepatu mampu mengetahui kekuatan dan kelemahan serta peluang dan ancaman sehingga dapat merumusan strategi agar perusahaan mampu bersaing dan bertahan dalam jangka panjang.

Data internal perusahaan diperoleh melalui wawancara dan kuesioner terhadap pihak manajemen PT XYZ, sedangkan data eksternal diperoleh malalui wawancara dan kuesioner terhadap pihak eksternal. Wawancara dan alat bantu kuesioner dilakukan untuk mendiskripsikan visi dan misi perusahaan, mengidentifikasi faktor internal dan eksternal serta serta mengetahui tingkat persaingan industri. Penelitian ini dilakukan dengan pendekatan nonprobability sampling dengan teknik purposive sampling dengan memilih responden internal dari pihak manajemen perusahaan PT XYZ yang terdiri dari Bapak AJ (Chief Financial Officer), Bapak TK (Direktur Operasional), Bapak RB (Asisten Direktur), Bapak RS (ManajerPD), BapakLS(Manajer Marketing) dan pihak eksternal yang berhubungan dengan industri sepatu, yaitu Bapak BM (Sekjen Aprisindo), Ibu AS (Akademisi) dan Bapak AS (Praktisi).
Teknik analisis yang dikembangkan dalam penelitian ini dilakukan menggunakan beberapa langkah yaitu menganalisis lingkungan internal dan eksternal dengan matrix Internal Factor Evaluation (IFE) dan External FactorEvaluation(EFE), menganalisis posisiperusahaan dengan matrix Internal-External (IE), perumusan strategi alternatif berdasarkan posisi perusahaan pada matrik IE, penyusunan rekomendasi prioritas strategi dengan Quantitative Strategic Planning Matrix (QSPM), selanjutnya adalah penentuan strategi bisnis.

Berdasarkan kerangka berpikir pada Gambar 2, langkah awal yang dilakukan dalam formulasi strategi PT XYZ ini adalah melakukan analisis visi dan misi perusahaan. Langkah berikutnya adalah melakukan analisis industri foresight untuk mengetahui gambaran industri sepatu di masa depan. Tahap berikutnya adalah melakukan analisis lingkungan untuk mengetahui posisi perusahaan. Analisis lingkungan terdiri dari lingkungan internal dan eksternal. Analisis lingkungan internal dilakukan melalui analisis fungsional dan analisis biaya strategik. Analisis internal ini untuk mengambarkan kekuatan dan kelemahan perusahaan. Hasil analisis internal disajikan dalam bentuk matrik IFE. Analisis lingkungan eksternal dilakukan melalui analisis PESTEL (Politik, Ekonomi, Sosial, Teknologi, Environment/Lingkungan dan Legal/ Hukum) dan analisis lima kekuatan Porter (Five Forces Porter).Analisislingkunganeksternalakanmenghasilkan peluang dan ancaman perusahaan. Hasil analisis eksternal disajikan dalam bentuk matrik EFE. Kombinasi matrik IFE dan EFE memposisikan perusahaan pada sel tertentu pada matrik IE untuk menentukan alternatif strategi yang bisa direkomendasikan untuk perusahaan. Langkah berikutnya adalah menentukan alternatif strategi yang dilakukan dengan matrik QSPM.

\section{HASIL}

\section{Deskripsi Visi dan Misi PT XYZ}

Visi PT XYZ adalah menjadi perusahaan sepatu kulit terkemuka yang membina sumber daya manusia yang mempunyai tekad kuat untuk menghasilkan keuntungan yang berkesinambungan. Berdasarkan hasil wawancara semua responden internal, disebutkan bahwa visi perusahaan saat ini sudah sesuai dengan cita-cita yang ingin dicapai perusahaan dalam jangka Panjang dan belum perlu dilakukan penyempurnaan maupun perubahan. 


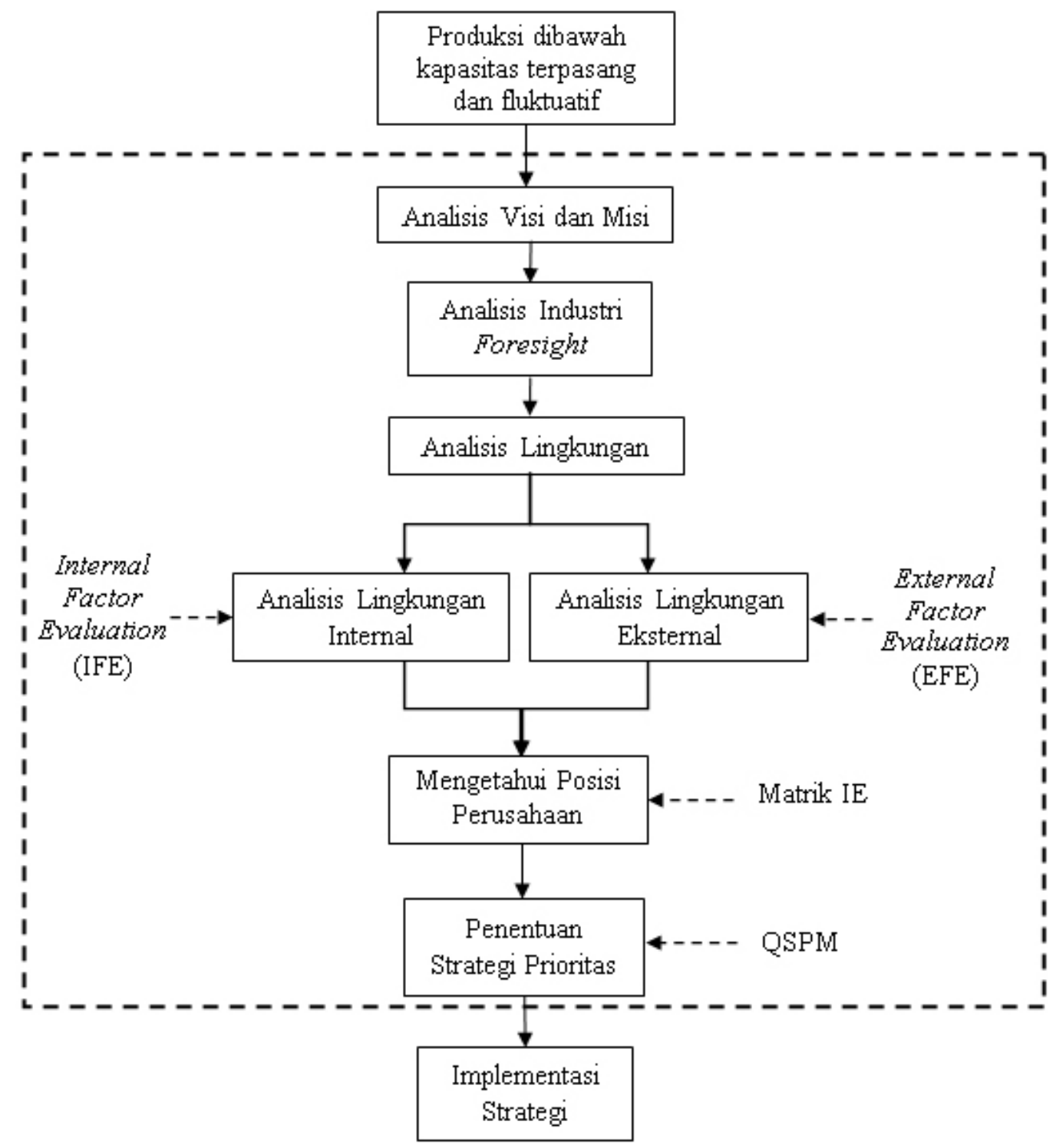

Gambar 2. Kerangka pemikiran penelitian

Hasil analisis misi, PT XYZ lebih fokus untuk mempublikasikan visi dan nilai inti perusahaan. Misi perusahaan antara lain 1) menciptakan produk yang berkualitas dengan harga yang kompetitif, 2) senantiasa berupaya meningkatkan kepuasan pelanggan dengan produk yang berkualitas dan pengiriman tepat waktu, 3) meningkatkan produktivitas untuk menurunkan biaya produksi, 4) meningkatkan skill karyawan dengan pelatihan dan program multiple skill, 5) mengembangkan own brand. Misi perusahaan ini bisa berubah sesuai dengan tuntutan bisnis.

Setelah analisis visi dan misi, langkah berikutnya dilakukan analisis industri foresight. Analisis ini untuk melihat kecenderungan perubahan dimasa depan dengan melihat kecenderungan perubahan teknologi, demografi, regulasi, gaya hidup dan geopolitik. Hal ini dilakukan untuk memastikan visi dan misi perusahaan masih sesuai dengan kecenderungan bisnis dimasa depan. Kecenderungan perubahan teknologi dibidang sepatu adalah beralihnya teknologi dari manual ke mesin dan berkembangnya elektronik marketing. Analisis trend berdasarkan demografi, mengalisis kecenderungan permintaan yang dipengaruhi oleh perubahan jumlah penduduk, persebaran penduduk, dan komposisi penduduk. Kenaikan jumlah penduduk setiap tahun merupakan pasar potensial untuk industri sepatu. Persebaran penduduk yang belum merata menyebabkan tidak meratanya permintaan. Kecenderungan perubahan karena faktor regulasi yaitu adanya kebijakan pemerintah yang mendukung industri sepatu. Pemerintah sangat mendukung industri yang berorientasi ekspor. Berbagai kebijakan diberikan untuk mempermudah perdagangan ekspor-impor. Perusahaan sepatu merupakan perusahaan labor intensive. Pemerintah juga mendukung bisnis sepatu karena dapat 
menyerap banyak tenaga kerja sehingga mengurangi pengangguran. Salah satu kebijakan pemerintah yang mendukung industri sepatu kulit adalah dihapuskannya sistem karantina yang memudahkan para pengusaha sepatu kulit untuk mendatangkan bahan baku impor. Perubahan gaya hidup mengalami kecenderungan untuk menyukai sepatu sneakers. Berdasarkan aspek geopolitik bisnis sepatu di Indonesia diperkirakan akan semakin berkembang karena secara geografis Indonesia terletak pada posisi yang sangat strategis dalam interaksi global karena terletak diantara dua benua dan dua samudra.

\section{Analisis Lingkungan Internal dan Eksternal}

Analisis lingkungan dilakukan untuk mengetahui kekuatan, kelemahan, peluang dan ancaman perusahaan. Analisis lingkungan internal dilakukan dengan menganalisis aspek fungsional perusahaan dan menganalisis faktor-faktor yang menjadi variabel dalam analisis biaya strategik. Hasil analisis ini menghasilkan 16 faktor strategis internal yang paling berpengaruh terhadap PT XYZ. Setelah dilakukan rating penilaian terhadap para responden menghasilkan delapan faktor strategis yang menjadi kekuatan dan delapan faktor strategis yang menjadi kelemahan PT XYZ.

Analisis lingkungan eksternal dilakukan dengan teknik analisis PESTEL dan five forces porter. Analisis PESTEL untuk menganalisis lingkungan makro dan analisis five forces porter untuk mengetahui kondisi persaingan industri. Hasil analisis ini menghasilkan 14 faktor strategis eksternal yang paling berpengaruh terhadap bisnis sepatu. Setelah dilakukan rating penilaian oleh para responden menghasilkan tujuh faktor strategis yang menjadi peluang dan tujuh faktor strategis yang menjadi ancaman untuk PT XYZ.

Pada analisis biaya strategik, dilakukan penentuan rating nilai oleh para responden juga dilakukan analisis tersendiri terhadap biaya strategik. Analisis biaya strategik untuk mengetahui keunggulan kompetitif PT XYZ terhadap perusahaan pesaing. Untuk mempermudah analisis perusahaan yang menjadi pesaing PT XYZ digunakan simbol dengan huruf dan angka. Kode huruf dan angka yang digunakan untuk simbol negara pesaing pada analisis biaya strategik ini secara rinci dapat dilihat pada Tabel 1.
Tabel 1. Kompetitor PT XYZ

\begin{tabular}{lcc}
\hline Negara & Kota & Simbol \\
\hline Vietnam & Hai Duong & $\mathrm{V}$ \\
Cina & Zhongshan & $\mathrm{C} 1$ \\
Cina & Qingdao & $\mathrm{C} 2$ \\
Cina & Zhuhai & $\mathrm{C} 3$ \\
Bangladesh & Delhi & $\mathrm{B} 1$ \\
Bangladesh & Dahka & $\mathrm{B} 2$ \\
Indonesia & Sidoarjo & $\mathrm{I} 1$ \\
Indonesia & Subang & $\mathrm{I} 2$ \\
Indonesia & Serang & $\mathrm{I} 3$ \\
\hline
\end{tabular}

Pendekatan yang dilakukan pada analisis biaya strategik, yaitu dengan analisis value chain. Analisis value chain dilakukan dengan menganalisis rangkaian kegiatan yang dilakukan PT XYZ untuk menghasilkan produk atau jasa. Parameter yang digunakan sebagai pembanding adalah biasa transportasi, UMP (Upah Minimum Regional), biaya pengiriman, biaya promosi atau pemasaran dan biaya yang harus ditanggung oleh perusahaan karena klaim pelanggan. Hasil analisis biaya strategik PT XYZ dapat dilihat pada Tabel 2.

\section{Perumusan Strategi}

Pada analisis IFE, penilaian kekuatan dan kelemahan digunakan nilai 1 sampai dengan 4. Nilai 1 (kelemahan utama), 2 (kelemahan kecil), 3 (kekuatan kecil), 4 (kekuatan utama). Hasil analisis IFE, sebagian besar variabel kekuatan yang dimiliki perusahaan merupakan kekuatan utama dan sebagian besar variabel kelemahan adalah kelemahan kecil. Kemampuan mempertahankan loyalitas mempunyai skor tertinggi karena sebagai perusahaan OEM loyalitas pelanggan merupakan faktor utama yang harus dipertahankan untuk menjaga kontinuitas pesanan. Hasil analisis IFE dan variabel yang menjadi kekuatan serta kelemahan perusahaan dapat dilihat pada Tabel 3 .

Pada penilaian peluang dan ancaman perusahaan digunakan nial 1 sampai dengan 4. Nilai 1 (ancaman utama), 2 (ancaman kecil), 3 (peluang kecil), 4 (peluang utama). Hasil analisis EFE, peluang utama perusahaan adalah kemampuan dalam Analisis Mengenai Dampak Lingkungan (AMDAL). Hal ini disebabkan karena perusahaan yang terletak ditengah pemukiman warga, AMDAL merupakan faktor penting untuk menjaga keberlangsungan perusahaan. Hasil penilaian sebagaian besar variabel peluang menunjukkan nilai 3 , hal ini menunjukkan bahwa sebagian besar variabel peluang merupakan peluang kecil, sedangkan sebagian besar 
ancaman merupakan ancaman kecil karena nilainya 2 . Hasil analisis EFE dan variabel yang menjadi peluang serta ancaman perusahaan dapat dilihat pada Tabel 4.

Penggabungan untuk memetakan faktor strategis perusahaan ke dalam sembilan kuadran yang terbagi menjadi tiga kelompok dan disebut matriks IE.
Penentuan koordinat dilakukan melalui IFE dan EFE. Hasil analisis IFE dan EFE menghasilkan skor 3,064;2,595. Penggabungan IFE dan EFE meletakkan perusahaan pada matrik IE, yaitu pada kuadran 1(sel IV). Pada bagian ini menunjukkan perusahaan dalam kondisi tumbuh dan membangun.

Tabel 2. Analisis biaya strategik

\begin{tabular}{|c|c|c|c|c|c|c|c|c|c|c|}
\hline Pendekatan rantai nilai (Value Chain) & Parameter & $\mathrm{V}$ & $\mathrm{C} 1$ & $\mathrm{C} 2$ & $\mathrm{C} 3$ & B1 & B2 & I1 & $\mathrm{I} 2$ & I3 \\
\hline Proses mendatangkan bahan baku & Biaya Transportasi & 3 & 3 & 3 & 3 & 1 & 1 & 2 & 2 & 2 \\
\hline Proses penciptaan produk & UMP & 3 & 1 & 3 & 1 & 3 & 3 & 1 & 3 & 3 \\
\hline $\begin{array}{l}\text { Proses penyampaian produk ke } \\
\text { konsumen }\end{array}$ & Biaya Pengiriman & 2 & 2 & 2 & 2 & 2 & 2 & 2 & 2 & 2 \\
\hline Marketing dan Sales & $\begin{array}{l}\text { Biaya promosi atau } \\
\text { pemasaran }\end{array}$ & 2 & 2 & 2 & 2 & 2 & 2 & 2 & 2 & 2 \\
\hline Service & Biaya klaim & 3 & 3 & 3 & 3 & 3 & 3 & 3 & 1 & 3 \\
\hline
\end{tabular}

Keterangan: 1 = Biaya PT XYZ lebih kecil dari perusahaan yang lain; 2 = Biaya PT XYZ sama dengan perusahaan yang lain; 3 = Biaya PT XYZ lebih tinggi dari Perusahaan yang lain.

Tabel 3. Rekapitulasi IFE

\begin{tabular}{|c|c|c|c|}
\hline Faktor strategis internal & Bobot & Nilai & Skor \\
\hline \multicolumn{4}{|l|}{ Kekuatan } \\
\hline Kemampuan manajemen dalam pengawasan sangat baik & 0,072 & 4 & 0,288 \\
\hline Loyalitas pelanggan yang tinggi & 0,079 & 4 & 0,315 \\
\hline Modal perusahaan yang kuat & 0,073 & 4 & 0,292 \\
\hline Setiap tahap pengembangan produk diselesaikan tepat waktu & 0,065 & 4 & 0,258 \\
\hline Adanya sistem informasi yang terintegrasi & 0,070 & 4 & 0,282 \\
\hline Kemudahan akses penyampaian produk ke tangan konsumen & 0,067 & 4 & 0,267 \\
\hline Struktur organisasi yang jelas & 0,068 & 4 & 0,273 \\
\hline Harga jual produk yang bersaing & 0,076 & 3 & 0,229 \\
\hline \multicolumn{4}{|l|}{ Kelemahan } \\
\hline Ketersediaan SDM yang belum sesuai kebutuhan & 0,051 & 2 & 0,103 \\
\hline Sasaran dan tujuan perusahaan belum terkomunikasikan dengan baik & 0,046 & 2 & 0,093 \\
\hline Pesanan pelanggan dalam jangka panjang belum bisa diprediksikan & 0,055 & 2 & 0,109 \\
\hline Mesin dan sumberdaya belum dimanfaatkan secara optimal & 0,057 & 2 & 0,113 \\
\hline Kemampuan mendatangkan bahan baku masih lemah & 0,052 & 2 & 0,103 \\
\hline Proses produksi belum efisien & 0,053 & 2 & 0,106 \\
\hline Proses pemasaran masih lemah & 0,054 & 2 & 0,108 \\
\hline Pelayanan ke konsumen belum sesuai tuntutan pelanggan & 0,063 & 2 & 0,126 \\
\hline Total & 1,000 & 47 & 3,064 \\
\hline
\end{tabular}


Tabel 4. Rekapitulasi EFE

\begin{tabular}{|c|c|c|c|}
\hline Faktor Strategis Eksternal & Bobot & Nilai & Skor \\
\hline \multicolumn{4}{|l|}{ Peluang } \\
\hline Analisis Dampak Lingkungan (AMDAL) & 0,070 & 4 & 0,281 \\
\hline Kebijakan pemerintah dalam mendukung industri sepatu kulit & 0,084 & 3 & 0,252 \\
\hline Situasi politik dan keamanan dalam negeri & 0,087 & 3 & 0,262 \\
\hline Meningkatnya gaya hidup (lifestyle) & 0,069 & 3 & 0,206 \\
\hline Hubungan dengan stakeholders & 0,069 & 3 & 0,208 \\
\hline Perkembangan teknologi dan komunikasi & 0,074 & 3 & 0,223 \\
\hline Pertumbuhan industri sepatu dimasa mendatang & 0,070 & 3 & 0,211 \\
\hline \multicolumn{4}{|l|}{ Ancaman } \\
\hline Kenaikan UMP & 0,076 & 2 & 0,153 \\
\hline Fluktuasi nilai tukar mata uang & 0,082 & 2 & 0,164 \\
\hline Undang-undang No 13 Tahun 2003 pasal 158 ayat 3 dan 4 & 0,066 & 2 & 0,132 \\
\hline $\begin{array}{l}\text { Jumlah pemasok kulit sebagai bahan baku sepatu masih terbatas sehingga mempunyai } \\
\text { kekuaan menentukan harga }\end{array}$ & 0,063 & 2 & 0,125 \\
\hline Pelanggan hanya 1 brand sehingga mempunyai kekuatan menekan harga & 0,061 & 2 & 0,122 \\
\hline Ancaman produk substitusi & 0,064 & 2 & 0,129 \\
\hline Kemampuan yang dimiliki pesaing & 0,064 & 2 & 0,127 \\
\hline Total & 1 & 36 & 2,595 \\
\hline
\end{tabular}

Berdasarkan analisis dengan menggabungkan matrik IE menghasilkan alternatif strategi yang bisa dilakukan di PT XYZ adalah 1) Strategi penetrasi pasar, strategi ini terbuka karena adanya loyalitas dari pelanggan. Sebagai perusahaan OEM, hal-hal yang dapat dilakukan oleh PT XYZ pada strategi penetrasi pasar ini antara lain meningkatkan performance perusahaan dan share informasi dengan pelanggan. Hal-hal yang bisa dilakukan untuk meningkatkan performance ini antara lain selalu memberikan update mengenai status development produk, status pesanan dan status pengiriman. Selain itu, PT XYZ juga harus selalu melakukan pendekatan dengan membangun komunikasi yang baik untuk meningkatkan loyalitas pelanggan. 2) Strategi pengembangan produk, strategi ini terbuka karena banyaknya permintaan model baru dari pelanggan, terutama sepatu canvas. 3) Strategi pengembangan Sumber Daya Manusia (SDM), strategi ini terbuka karena sebagai perusahaan labor intensive strategi ini sangat diperlukan untuk mendukung daya saing perusahaan. 4) Strategi pengembangan pasar, strategi ini terbuka karena mulai adanya permintaan dari negara-negara di luar Amerika. Saat ini pelanggan utama PT XYZ adalah dari negara Amerika. 5) Strategi relokasi perusahaan, strategi ini terbuka karena UMP dibeberapa daerah di Jawa Tengah masih lebih kecil dari pada di Jawa Barat. 6) Strategi menetapkan harga bersaing, strategi ini terbuka karena PT XYZ sudah mampu produksi efisien untuk model big volume. Pelanggan mempunyai model tertentu yang disebut big volume, yaitu model yang paling banyak dipesan oleh pelanggan karena paling laku dipasaran. Untuk model big volume ini PT XYZ sudah menguasai teknik produksinya. Produk yang proses produksinya sudah dikuasai, PT XYZ dapat melakukan efisiensi baik untuk material maupun prosesnya.

Hasil analisis dengan pendekatan matrik QSPM didapatkan bahwa strategi terpilih untuk PT XYZ sebagai perusahaan OEM adalah Pengembangan SDM. Meskipun strategi yang terpilih adalah Pengembangan SDM, strategi-strategi yang lain tetap diperhitungkan. Urutan prioritas strategi berdasarkan nilai TAS matrik QSPMdapat dilihat pada Tabel5. Melihat kebutuhan saat ini yang utama dan prioritas harus diimplementasikan adalah pengembangan SDM. Hal ini diperhitungkan karena adanya faktor-faktor strategis yang sudah didapat sebelumnya terutama loyalitas pelanggan yang tinggi. Loyalitas pelanggan bisa dipertahankan jika perusahaan mampu memberikan pelayanan yang baik. Pelayanan yang baik ini bisa terpenuhi jika perusahaan mempunya SDM yang berkualitas yang mampu menghasilkan produk yang berkualitas. 
Tabel 5. Urutan prioritas strategi PT XYZ

\begin{tabular}{lcc}
\hline Strategi alternatif & Total Attractive Score & Urutan prioritas \\
\hline Pengembangan SDM & 5,940 & 1 \\
Pengembangan produk & 4,992 & 2 \\
Penetrasi pasar & 4,880 & 3 \\
Relokasi perusahan & 4,595 & 4 \\
Pengembangan pasar & 4,523 & 5 \\
Menetapkan harga bersaing & 3,941 & 6 \\
\hline
\end{tabular}

Sumber Daya Manusia (SDM) merupakan asset utama perusahaan sepatu sebagai perusahaan labor intensive. Strategi-strategi perusahaan yang lain seperti penetrasi pasar, pengembangan produk, pengembangan pasar hanya bisa diwujudkan jika perusahaan mempunyai SDM yang berkualitas. Demikian juga penetapan harga bersaing hanya bisa dilakukan jika produksi mampu menghasilkan produk yang berkualitas dan biaya produksi yang rendah.

Strategi Pengembangan SDM menjadi strategi terpilih untuk diimplementasikan karena adanya beberapa faktor yang menjadi daya tarik perushaan yaitu loyalitas pelanggan yang tinggi, modal perusahaan yang kuat, adanya sistem informasi yang terintegrasi, struktur organisasi perusahaan yang jelas yang mempermudah pengembangan SDM dan kemampuan manajemen dalam pengawasan yang kuat.

\section{Implikasi Manajerial}

Penelitian ini diharapkan dapat memberikan manfaat kepada perusahaan dalam meningkatkan kepercayaan pelanggan PT XYZ sehingga kontinyuitas dan stabilitas pesanan bisa terjamin. Hasil penelitian, prioritas strategi yang direkomendasikan untuk perusahaan adalah pengembangan SDM. SDM saat ini, secara jumlah sudah sesuai dengan kebutuhan perusahaan tetapi masih ditemukan SDM yang spesifikasinya belum sesuai dengan kebutuhan dan masih ditemukan karyawan lama yang sulit mengikuti perubahan terutama yang berkaitan dengan teknologi baru. Untuk mengatasi kelemahan SDM tersebut maka langkah-langkah yang bisa dilakukan perusahaan antara lain: 1) Untuk mendapatkan SDM yang berkualitas harus berkualitas harus dimulai pada saat rekruitment, karyawan yang direkrut harus disesuaikan spesifikasinya dengan kebutuhan perusahaan, 2) perusahaan juga harus melakukan upgrade skill secara rutin dengan pelatihanpelatihan, pelatihan yang diberikan harus ke semua level karyawan baik staff maupun operator, 3) program multiple skill (karyawan dilatih untuk mempunyai keahlian lebih dari satu keahlian) diperlukan untuk mendukung kemampuan karyawan dan sangat diperlukan untuk mendukung sering bergantinya model sepatu yang dipesan pelanggan.

\section{KESIMPULAN DAN SARAN}

\section{Kesimpulan}

Visi perusahaan saat ini sudah sesuai dengan tujuan dan cita-cita perusahaan. Pada rumusan visi terdapat tiga hal yang ingin diwujudkan perusahaan yaitu menjadi perusahaan sepatu kulit terkemuka, membina sumber daya manusia dan menghasilkan keuntungan yang berkesinambungan. Pada analisis misi dapat diidentifikasi bahwa belum semua anggota perusahaan mengetahui misi perusahaan secara tertulis karena perusahaan saat ini lebih mementingkan menanamkan visi dan nilai inti perusahaan.

Hasil analisis lingkungan internal dan eksternal perusahaan berhasil diidentifikasi kekuatan, kelemahan, peluang dan ancaman perusahaan. Hasil analisis internal menghasilkan delapan faktor strategis yang menjadi kekuatan perusahaan dan delapan faktor yang menjadi kelemahan perusahaan. Hasil analisis eksternal menghasilkan tujuh faktor yang menjadi peluang dan tujuh faktor yang menjadi ancaman untuk PT XYZ.

Analisis kekuatan dan kelemahan pada matrik IFE menghasilkan skor 3,064. Skor ini menunjukkan bahwa secara internal perusahaan berada pada posisi kuat. Analisis peluang dan ancaman pada matrik EFE menghasil skor 2,595. dan menunjukkan bahwa perusahaan pada posisi rata-rata. Nilai skor IFE dan EFE $(3,064 ; 2,595)$ memposisikan perusahaan pada matrik IE yaitu kuadran I (sel IV). Pada kuadran ini strategi yang tepat adalah grow and build. Beberapa alternatif strategi yang berhasil dirumuskan antara lain penetrasi pasar, pengembangan produk, pengembangan SDM, pengembangan pasar, relokasi perusahaan 
dan menetapkan harga bersaing. Hasil analisis alternatif strategi, strategi prioritasnya adalah Strategi Pengembangan SDM. SDM merupakan asset utama perusahaan sepatu sebagai perusahaan labor intensive. Strategi-strategi perusahaan yang lain seperti penetrasi pasar, pengembangan produk, pengembangan pasar hanya bisa diwujudkan jika perusahaan mempunyai SDM yang berkualitas. Demikian juga penetapan harga bersaing hanya bisa dilakukan jika produksi mampu menghasilkan produk yang berkualitas dan biaya produksi yang rendah

\section{Saran}

Beberapa hal yang bisa disarankan oleh penulis setelah melakukan penelitian di PT XYZ adalah: 1) Perusahaan sepatu sebagai perusahaan labor intensive harus mengutamakan strategi pengembangan SDM karena SDM merupakan kekuatan utama perusahaan, 2) sebagai perusahaan OEM loyalitas pelanggan sangat diperlukan untuk menjamin kontinyuitas dan stabilitas pesanan sehingga perusahaan harus mewujudkan halhal yang menjadi tuntutan pelanggan, yaitu kualitas produk yang baik, pengiriman tepat waktu dan harga yang kompetitif, 3) perusahaan harus mengembangkan pasar dengan memperkuat tim marketing sehingga tidak hanya bergantung dengan satu pelanggan, 4) untuk penelitian selanjutnya disarankan penelitian yang lebih fokus pada strategi pengembangan produk own brand agar kedepannya penjualan own brand meningkat dan bisa menjadi produk utama perusahaan.

\section{DAFTAR PUSTAKA}

Bae YH. 2012. Three essays on the customer satisfactioncustomer loyalty association [thesis]. Iowa: The University of Iowa.

Bask AH, Tinnila M, Rajahonka M. 2010. Matching service strategies, business models and modular business processes. Business Process Management Journal 16(1):53-180. https://doi. org/10.1108/14637151011017994.

Bastian DA. 2014. Analisa pengaruh citra merek (brand image) dan kepercayaan merek (brand trust) terhadap loyalitas merek (brand loyalty) ADES PT Ades Alfindo Putra Setia. Jurnal Manajemen Pemasaran Petra 2(1):1-9.

Biodi M, Sanawiri B. 2017. Analisis lingkungan industri guna menentukan business strategi dalam rangka mencapai keunggulan bersaing (studi kasus pada PT Alfi Putra). Jurnal Administrasi Bisnis 50(3):172-181.

Chen D, Wei W, Hu D, Muralidharan E. 2015. Survival strategy of OEM companies: a case study of the Chinese toy industry. International Journal of Operations \& Production Management 36(9):1065-1088.https://doi.org/10.1108/ IJOPM-04-2015-0212.

Chen J. 2010. Reasons for the transition of the processing trade industry from OEM to OBM: case study: Hangzhou Alpha Imp \& Exp Co., Ltd [thesis]. Kajaani: Kajaani University of Applied Sciences.

Ehie I, Muogboh O. 2016. Analysis of manufacturing strategy in developing countries (a sample survey of Nigerian manufacturers). Journal of Manufacturing Technology Management 27(2):234-260. https://doi.org/10.1108/JMTM07-2014-0094.

Hashim MK. 2016. Approaches to formulating business strategy. Arabian Journal of Business and Management 7(1):1-7.

Hutahaean R, Fahmi I, Yusuf AM. 2017. Formulasi strategi bisnis PT XYZ. Jurnal Aplikasi Bisnis dan Manajemen 3(3): 447-457.

Li J. 2013. Factors affecting customer satisfaction and customer loyalty towards Belle Footwear company in Lanzhou City, Gansu Province of the People's Republic of China. IOSR Journal of Business and Management 14(2):41-48. https:// doi.org/10.9790/487X-1424148.

Normasari S, Kumadji S, Kusumawati S. 2013. Pengaruh kualitas pelayanan terhadap kepuasan pelanggan, citra perusahaan dan loyalitas pelanggan. Jurnal Administrasi Bisnis 6(2):1-9.

Nurseto S. 2012. Analisis pengaruh lingkungan industri terhadap strategi pemasaran dan dampaknya terhadap kinerja pemasaran (studi pada usaha kecil Kerajinan Kulit Tanggulangin. Jurnal Administrasi Bisnis 1(1):72-83.

Nurzamzami A. 2016. Peningkatan daya saing UMKM alas kaki di Kecamatan Ciomas, Kabupaten Bogor dan implikasinya terhadap strategi pemasaran. Jurnal Manajemen dan Organisasi 5(1):15-29. https://doi.org/10.29244/jmo.v5i1.12127.

Osita IF, Onyebuchi I, Justina N. 2014. Organization's stability and productivity: the role of SWOT analysis an acronym for strength, weakness, opportunities and threat. International Journal 
of Innovative and Applied Research 2(9):23-32.

Piri HG. 2013. Kualitas pelayanan jasa pengaruhnya terhadap loyalitas pelanggan pada Steiner Salon Manado. Jurnal Jurnal Ekonomi, Manajemen, Bisnis dan Akutansi 1(4):504-512.

Prasad A. 2010. Strategy as inferior choice, a reinterpretation of Porter's what is strategy? Journal of Management Research 10(1):15-24.

Ribek PK. 2016. Formulasi strategi bersaing dan implikasinya terhadap kinerja pemasaran pada Gallery Yansugem Art and Design. Jurnal Bakti Saraswati 5(1):1-6.

Rivai A, Prawironegoro D. 2015. Manajemen Strategis. Jakarta: Mitra Wacana Media.
Singh R. 2016. Factors affecting brand loyalty in the footwear industry-study of Ludhiana District. International Journal of Research Granthaalayah 4(6):139-149.

Wicaksono A. 2017. Strategi pemasaran dengan menggunakan analisis SWOT tanpa skala industri pada PT X di Jakarta. Jurnal Manajemen Industri dan Logistik 1(2):106-112.

Yan H, Chiang C, Chien CS. 2011. From original equipment manufacturing to branding: entrepreneurship, strategic leadership, and Taiwan's firm transformation. Journal of International Entrepreneurship and Management 10(1):81-102. https://doi.org/10.1007/s11365011-0213-0. 